\title{
Selected aspects of diagnosing material removal machining processes state
}

\author{
Robert Polasik ${ }^{1,}$, , Janusz Musiał ${ }^{1}$, Jarosław J asik ${ }^{1}$, Igor K ovtun ${ }^{2}$ and Aleksandr Povareho ${ }^{3}$ \\ ${ }^{1}$ Faculty of Mechanical Engineering, University of Science and Technology, Kaliskiego 7 Street, \\ 85-789 Bydgoszcz, Poland \\ ${ }^{2}$ K hmelnytsky National U niversity, 29016, 11 Institutska Street, K hmelnytsky, U kraine \\ ${ }^{3}$ B elarusian N ational Technical University, 220013 M insk, Nezavisimosti, 65, B elarus
}

\begin{abstract}
The article presents the results of works on the analysis of the possibility of using force measurements to determine the state of the machining process, both in relation to the phenomena occurring during machining and the workpiece itself compared to acoustic emission signal $(A E)$. The research and analyzes were carried out for the commonly used material removal processes of objects; turning, milling, grinding and drilling. $V$ arious materials were processed - metal alloy Hardox 400 as well as fiber composite materials (GFRP - Glass Fiber Reinforced Polymer) and polymer construction material RenShape ${ }^{\circledR}$ BM5035 with various structures. As a result of the conducted analyzes, it was determined that the forces generated in the machine tool-holder-w orkpiece-tool layout can constitute a good diagnostic signal, on the basis of which it is possible to conclude about the state of the process.
\end{abstract}

\section{Introduction}

The term "diagnosing of a state" has been adopted as determination of all activities that lead, by measuring or defining a diagnostic signal, to indicate symptoms that may indicate correct or incorrect operation (state) - most often in relation to the machine [1]. Diagnosing the state can also be implemented in relation to determining the correctness of phenomena, occurring during various types of treatments. There are terms used in technology such as: "process monitoring", e.g. using acoustic emission [2-4] and "trouble diagnosis" [5] in relation to changes occurring in time (variable over time) during objects machining. In such an approach, the diagnosis process can be indicated as diagnosing a condition of the process.

Recently, a significant increase in the number of studies on new or modified materials can be observed [6-8], which should then be further processed - in this area, due to the previously unrecognized behaviourism of the shaping process, the processes of their formation should be diagnosed. Among the many existing machining processes, works related to determining the state of the process (diagnosis) are particularly often described for: turning [9-17], milling[18-22], grinding [23-24] and drilling [25]. On the basis of the literature review, the physical phenomena that are most often used as the source of diagnostic signals were distinguished. They are: temperature [26], vibrations [27], forces [28-30] and acoustic emission (AE) [31-32] or audible energy sound [33]. These are the values that indirectly an indicate the condition of the machining processes. The state of the process is determined by: the processed material - its properties, the machine tool and tool used - their condition; stiffness, ability to dampen vibrations, cutting edge condition, environment temperature, dry or machining using coolant.

* Corresponding author: robert.polasik@ utp.edu.pl 


\section{Characteristics and diagnosing of machining processes state}

An attempt was made to determine the suitability of the acoustic emission signal (as a measurement method that does not require interference with the system) and the forces generated in the tool-holder-workpiece system (as a method that requires interference with the system) for various processes; turning and milling and various materials: Hardox 400 alloy, fiber composite material (GFRP - Glass Fiber Reinforced Polymer) and polymer construction material RenShape ${ }^{\circledR}$ BM5035.

\subsection{General set-up, methodology and technique of experiments}

The article presents the results of original studies using the Kistler 9257B dynamometer with the 5017 signal amplifier. The set was supplemented with acoustic emission acquisition (AE) set: Kistler coupler $5125 \mathrm{C}$, (gain: x1, time constant: $0.12 \mathrm{~ms}$, hardware filter: $1 \mathrm{kHz}$ ), acoustic emission sensor $8152 \mathrm{C}(50 \div 400 \mathrm{kHz})$. The AE sensor has always been mounted vertically and separately from dynamometer, regardless of the orientation of the dynamometer axis.

The acquired and processed signal was sent to a data acquisition system for force measurements (DAQ) Type 5697A module. During the measurement of the grinding force and acoustic emission signal, the proprietary software Dynoware 2825D-02, supplied by the manufacturer of the dynamometer was used. The software had a database structure, which made possible to conduct collected data without the need to record the obtained results.

Before making the tests, the dynamometer was programmed in Newtons (based on the attached calibration card - the values are given in Table 1.) and checked by applying a force with a known value.

Table 1. 3-component Kisler 9257B dynamometer technical data.

\begin{tabular}{|c|c|c|c|}
\hline $\begin{array}{c}\text { Range } \mathrm{Fx}, \mathrm{Fy}, \mathrm{Fz} \\
\text { Fz for } \mathrm{Fx} \text { and } \mathrm{Fy} \leq 0,5 \mathrm{Fz}\end{array}$ & $\begin{array}{c}\mathrm{Fx}, \mathrm{Fy}, \mathrm{Fz} \\
\mathrm{Fz}\end{array}$ & $\begin{array}{l}\mathrm{kN} \\
\mathrm{kN}\end{array}$ & $\begin{array}{l}-5 \ldots 5 \\
-5 \ldots 10\end{array}$ \\
\hline Threshold & - & $\mathrm{N}$ & $<0,01$ \\
\hline Sensitivity (calibrated) & $\begin{array}{l}\text { Fx, } \\
\text { Fy } \\
\text { Fz }\end{array}$ & $\begin{array}{l}\mathrm{pC} / \mathrm{N} \\
\mathrm{pC} / \mathrm{N} \\
\mathrm{pC} / \mathrm{N}\end{array}$ & $\begin{array}{l}-7,92 \\
-7,90 \\
-3,69\end{array}$ \\
\hline Hysteresis, all ranges & - & $\% \mathrm{FSO}$ & $\leq 0,5$ \\
\hline Cross talk & - & $\%$ & $\leq \pm 2$ \\
\hline Natural frequency & $f_{n}(x, y, z)$ & $\mathrm{kHz}$ & $\approx 3,5$ \\
\hline $\begin{array}{l}\text { Natural frequency } \\
\text { (mounted on flanges }\end{array}$ & $\begin{array}{c}f_{n}(x, y) \\
f_{n}(z)\end{array}$ & $\begin{array}{l}\mathrm{kHz} \\
\mathrm{kHz}\end{array}$ & $\begin{array}{l}\approx 2,3 \\
\approx 3,5\end{array}$ \\
\hline
\end{tabular}

The obtained results were analysed and presented in the form of charts. $F_{x}, F_{y}, F_{z}$ - cutting force components and $\mathrm{AE}$ values changes during machining are presented in figures. Digitally unfiltered values (raw values) were analysed - in this case, a hardware low-pass filter of the amplifier $10 \mathrm{~Hz}$ and sample rate: $100 \mathrm{~Hz}$, marked as Stage 1 in the graphs, was used; e.g. Fig. 1.

Digital filtration was used - a low-pass filter $-3 \mathrm{~dB}, 5 \mathrm{~Hz}$ for the signal of the force components and the raw signal of acoustic emission - marked in the graphs as Stage 2; e.g. Fig. 2. 
Digital filtration was used - a low-pass filter $-3 \mathrm{~dB}, 5 \mathrm{~Hz}$ for the signal of force components and the acoustic emission signal - marked on the graphs as Stage 3; e.g. Fig. 3. The other conditions are listed in the individual paragraphs below.

\subsection{Turning process}

Polymer material turning conditions were:

- RenShape ${ }^{\circledR}$ BM 5035 material

- PTTNR-2525-16 toolholder and TNMG 1604 08-QM 4035 insert,

- cutting speed $\mathrm{v}_{\mathrm{c}},-126 \mathrm{~m} / \mathrm{min}$, kinematical feedrate $\mathrm{v}_{\mathrm{f}}-0,19 \mathrm{~mm} / \mathrm{rev}$, cutting depth $\mathrm{a}_{\mathrm{p}}=2 \mathrm{~mm}$,

RenShape ${ }^{\circledR}$ BM 5035 is a low density polyurethane with good dimensional stability. It is easy to machining. This material is used in the production of models and prototypes. As shown in the study [33], the BM5035 material is characterized by a relatively low resistance to intense friction.

Steel material turning conditions were:

- Hardox 400 material, average (measured) hardness: 45 HRC,

- PCLNR-2525-12 toolholder and CNMG 1204 08-PM 4325 insert,

- $\quad$ cutting speed $\mathrm{v}_{\mathrm{c}},-67 \mathrm{~m} / \mathrm{min}$, kinematical feedrate $\mathrm{v}_{\mathrm{f}}-0,05 \mathrm{~mm} / \mathrm{rev}$ and $0,19 \mathrm{~mm} / \mathrm{rev}$, cutting depth $\mathrm{a}_{\mathrm{p}}=0,2 \mathrm{~mm}$,

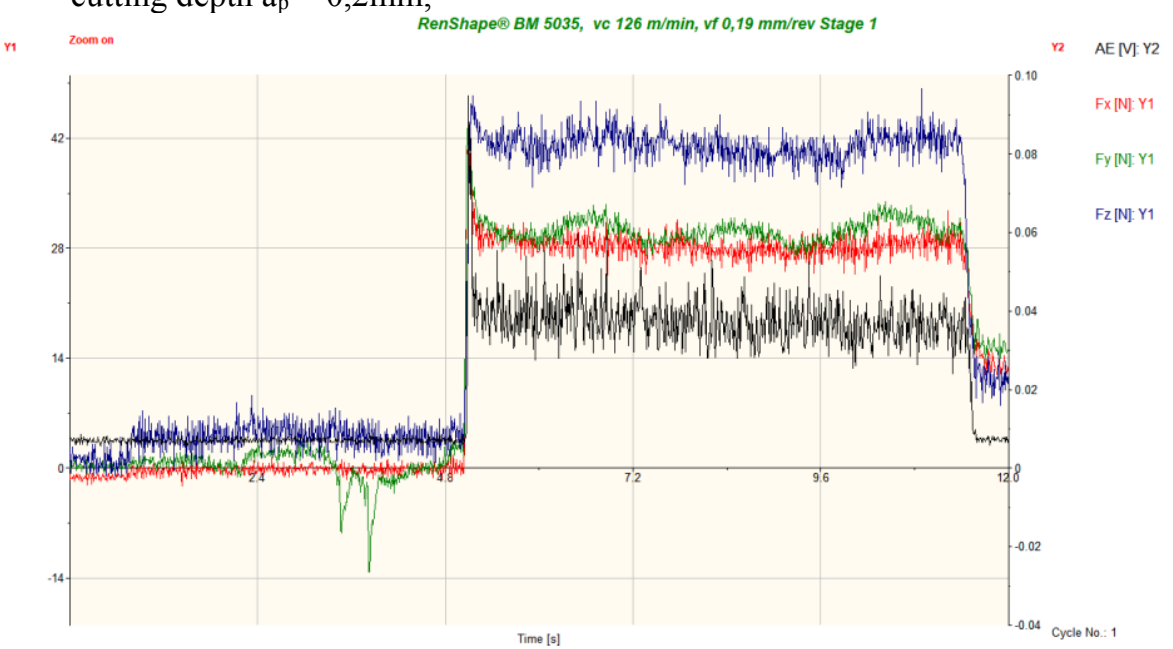

Fig. 1. $F_{x}, F_{y}, F_{z}$ and $A E$ values changes during turning RenShape ${ }^{\circledR} B M 5035$, Stage 1 . 


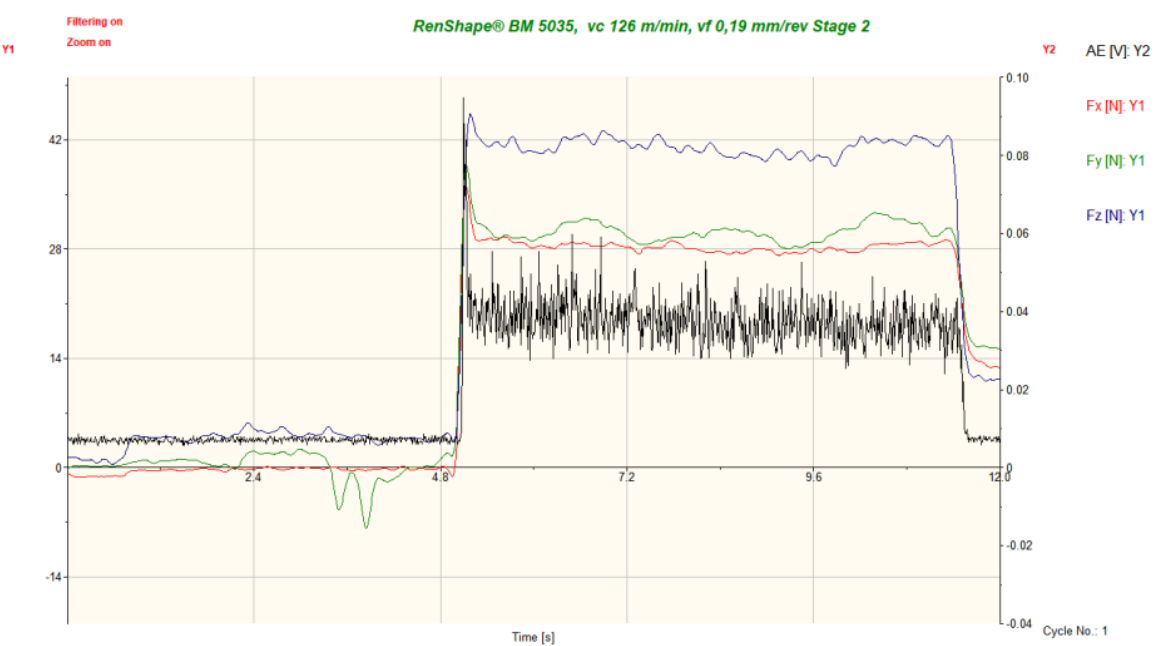

Fig. 2. $F_{x}, F_{y}, F_{z}$ and $A E$ values changes during turning RenShape ${ }^{\circledR}$ BM 5035, Stage 2.

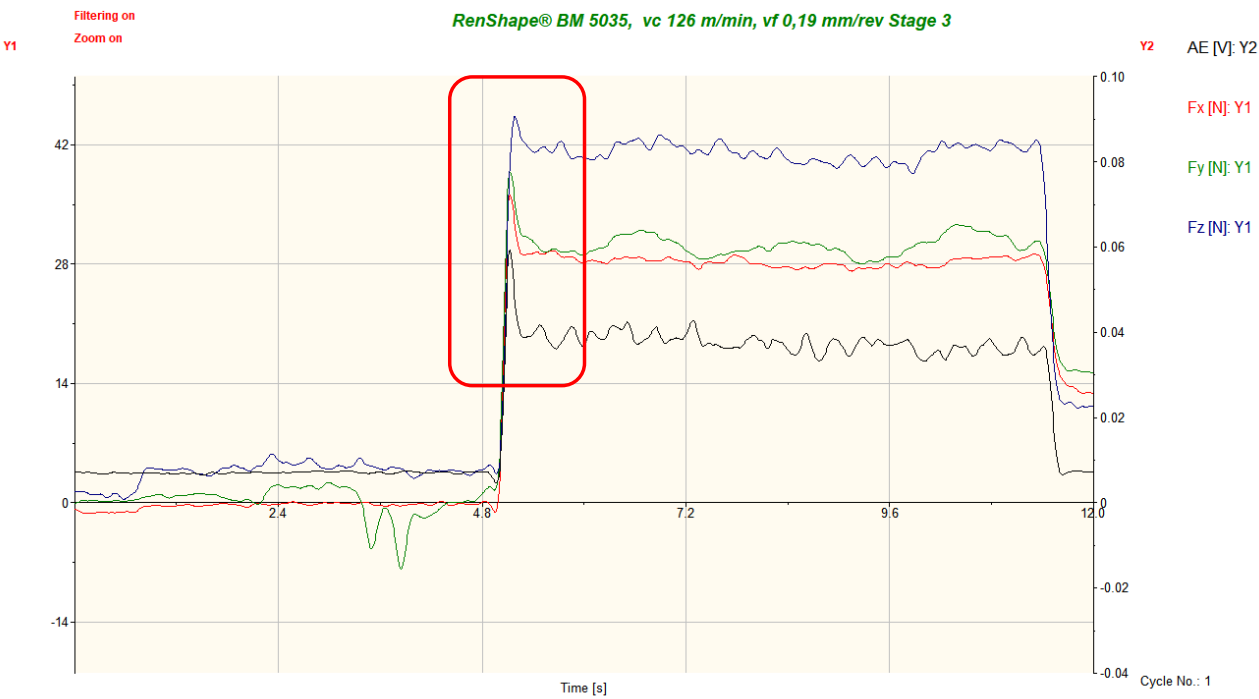

Fig. 3. $F_{x}, F_{y}, F_{z}$ and $A E$ values changes during turning RenShape ${ }^{\circledR}$ BM 5035, Stage 3. 


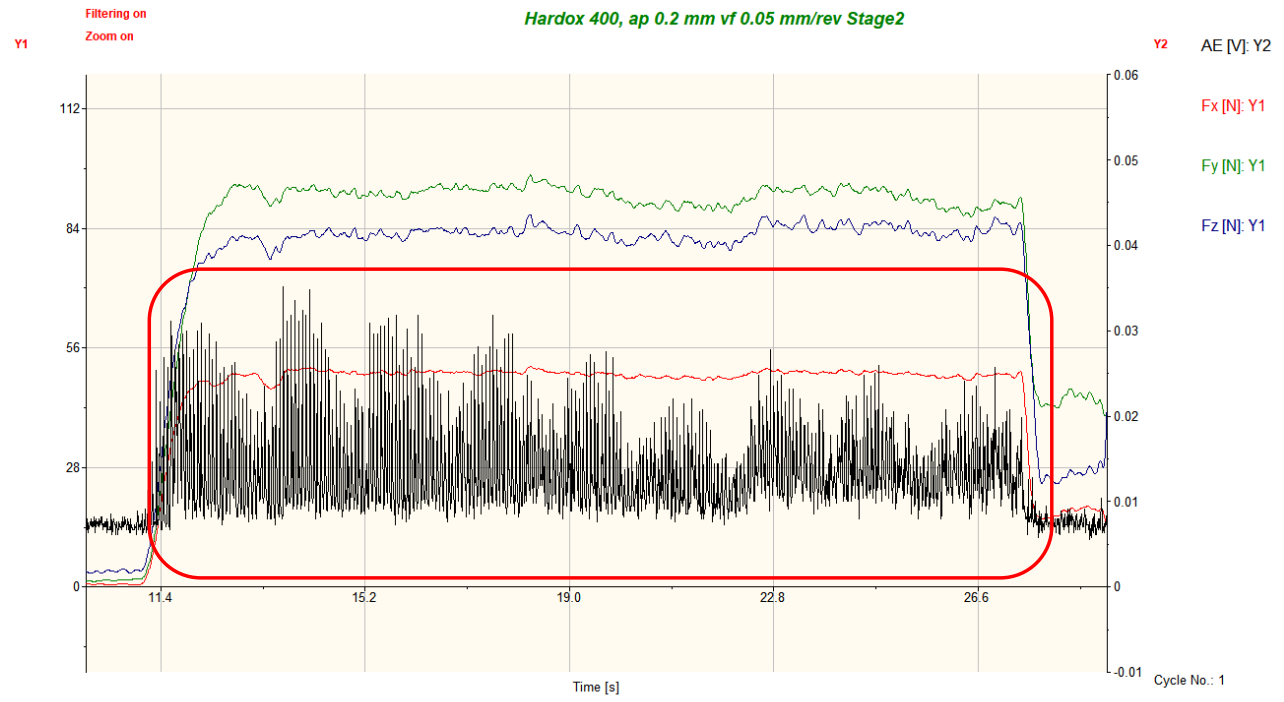

Fig. 4. $F_{x}, F_{y}, F_{z}$ and $A E$ values changes during turning $\left(v_{f}=0.05 \mathrm{~mm} / \mathrm{rev}\right)$ Hardox 400 , Stage 2.

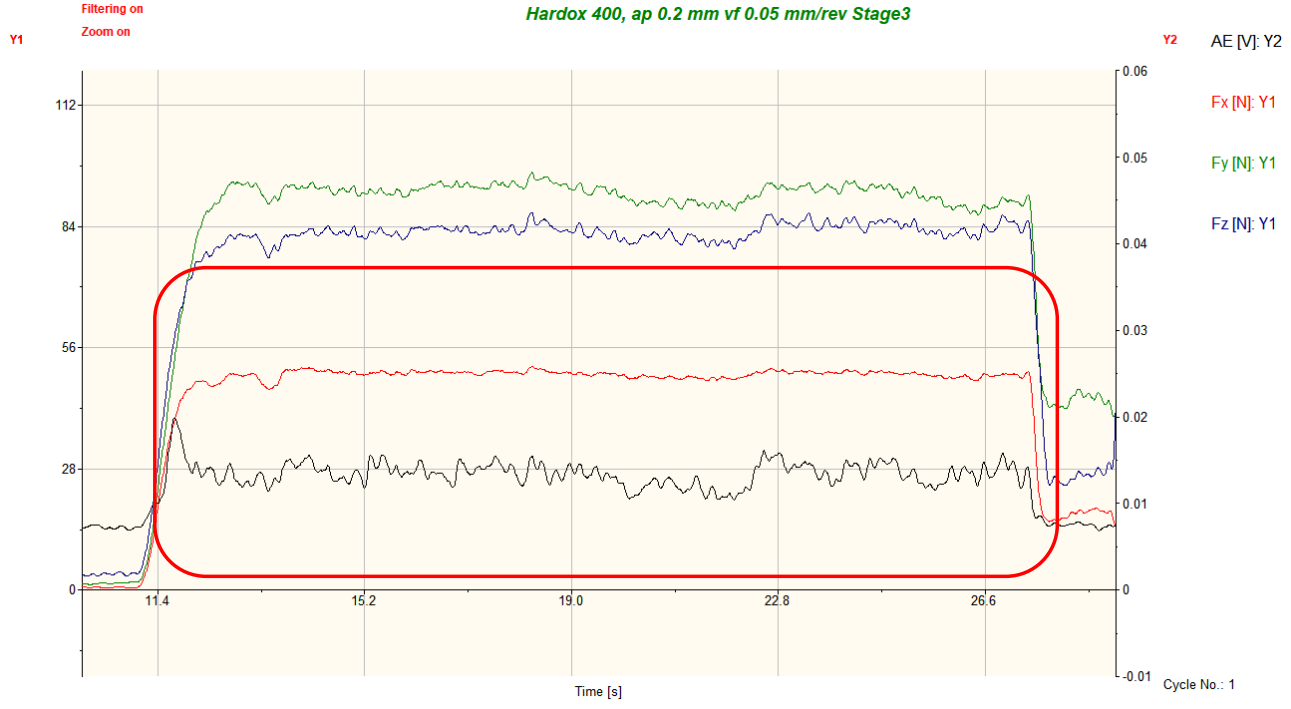

Fig. 5. $F_{x}, F_{y}, F_{z}$ and $A E$ values changes during turning $(v f=0.05 \mathrm{~mm} / \mathrm{rev})$ Hardox 400 , Stage 3 . 


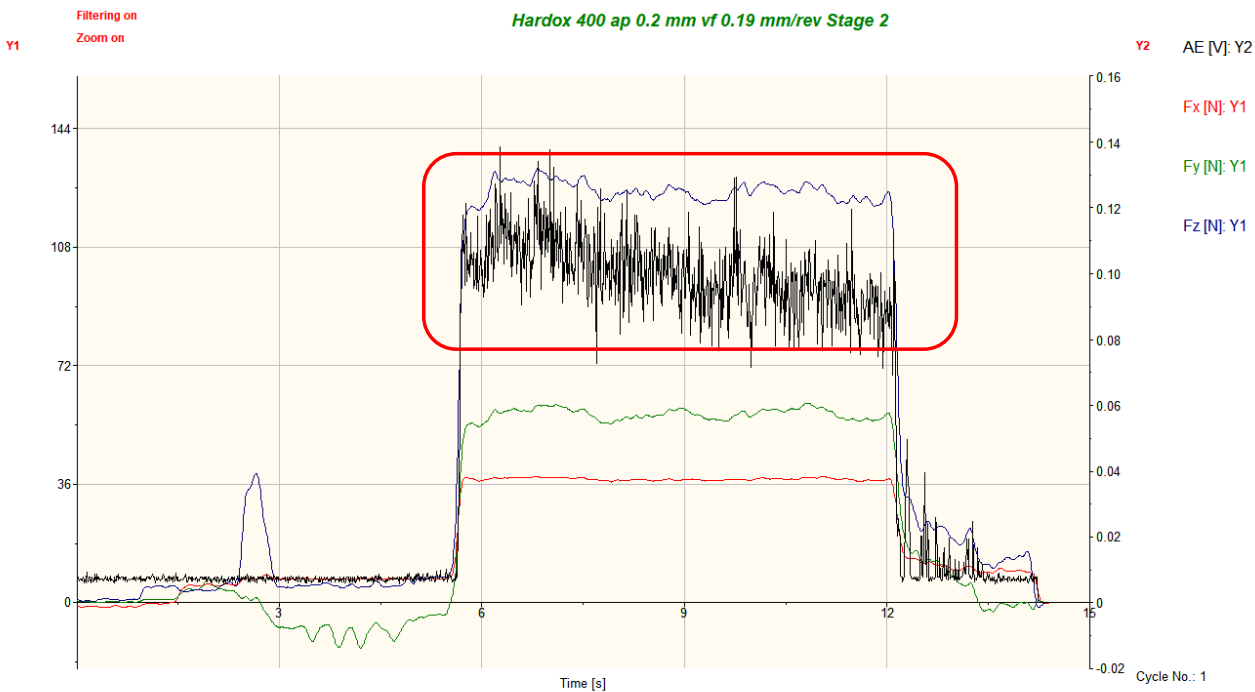

Fig. 6. $F_{x}, F_{y}, F_{z}$ and $A E$ values changes during turning $\left(v_{f}=0.19 \mathrm{~mm} / \mathrm{rev}\right)$ Hardox 400 , Stage 2 .

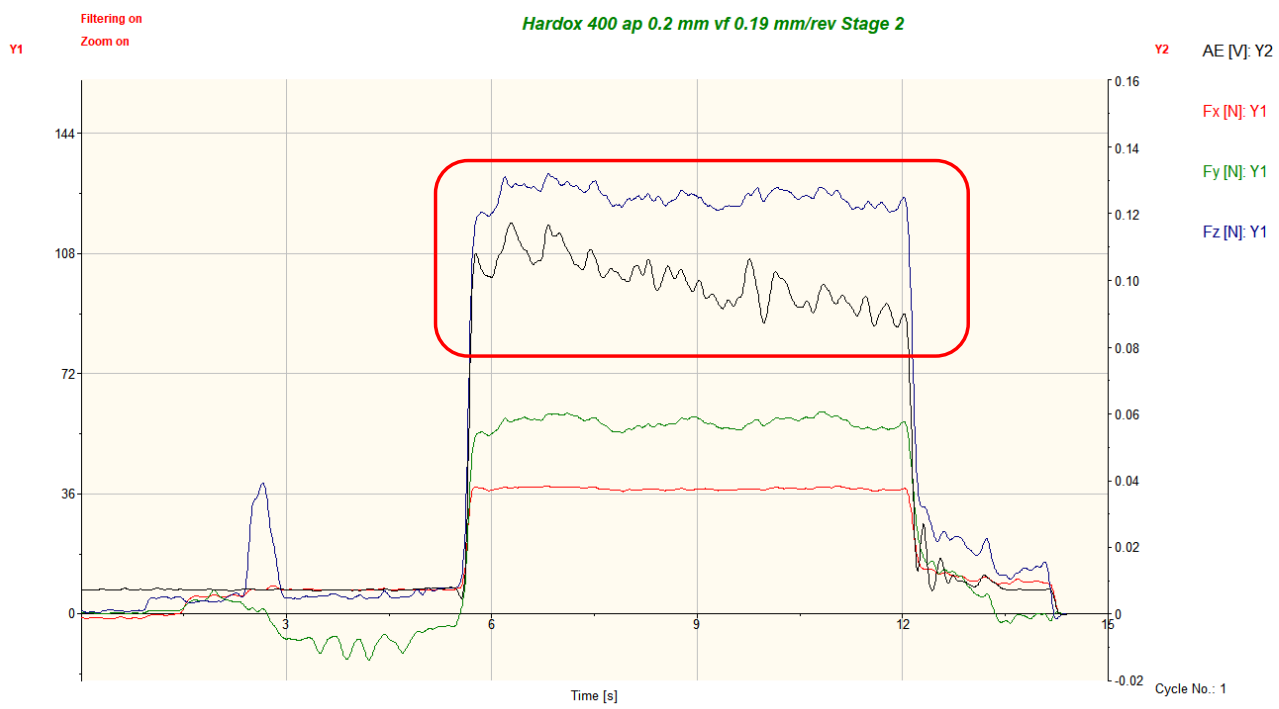

Fig. 7. $F_{x}, F_{y}, F_{z}$ and $A E$ values changes during turning ( $\left.v_{f}=0.19 \mathrm{~mm} / \mathrm{rev}\right)$ Hardox 400 , Stage 3.

\subsection{Milling process}

Main conditions during milling operation were;

- mill \#1 - Guhring 3715, diameter $12 \mathrm{~mm}$,

- mill \#2 - Sandvik Coro Mill Plural 2P460-1200-NA,

- GFRP - IDA hardener was used,

- cutting speed $\mathrm{v}_{\mathrm{c}},-30 \mathrm{~m} / \mathrm{min}$, feedrate $\mathrm{v}_{\mathrm{f}}-200 \mathrm{~mm} / \mathrm{min}$, cutting depth $\mathrm{a}_{\mathrm{p}}=10$ $\mathrm{mm}$, cutting width $\mathrm{a}_{\mathrm{e}}=1 \mathrm{~mm}$. 


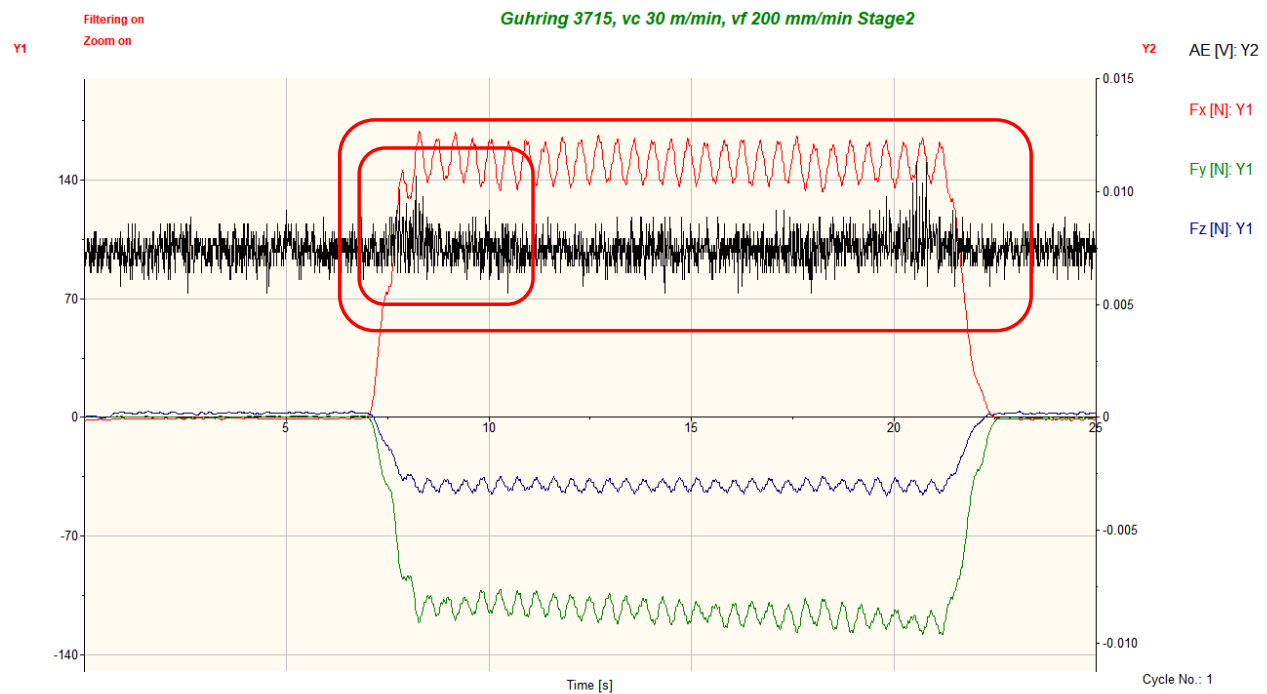

Fig. 8. $F_{x}, F_{y}, F_{z}$ and $A E$ values changes during milling GFRP with Guhring 3715 tool, Stage 2.

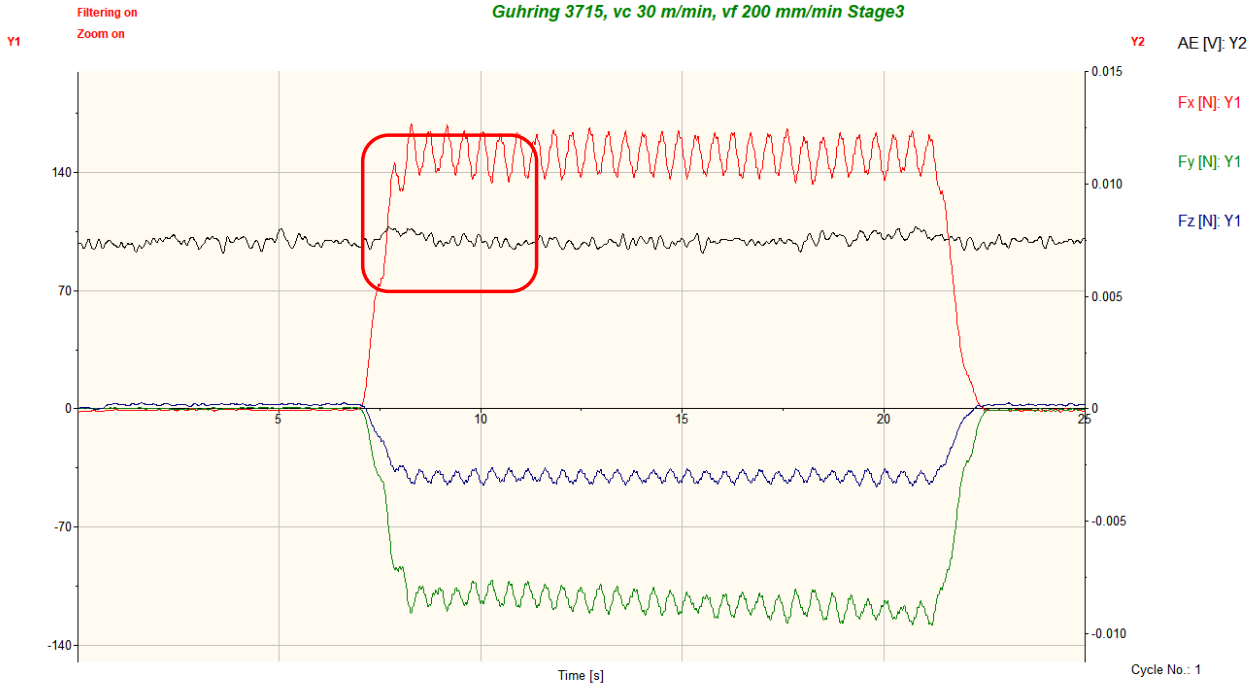

Fig. 9. $F_{x}, F_{y}, F_{z}$ and $A E$ values changes during milling GFRP with Guhring 3715 tool, Stage 3. 


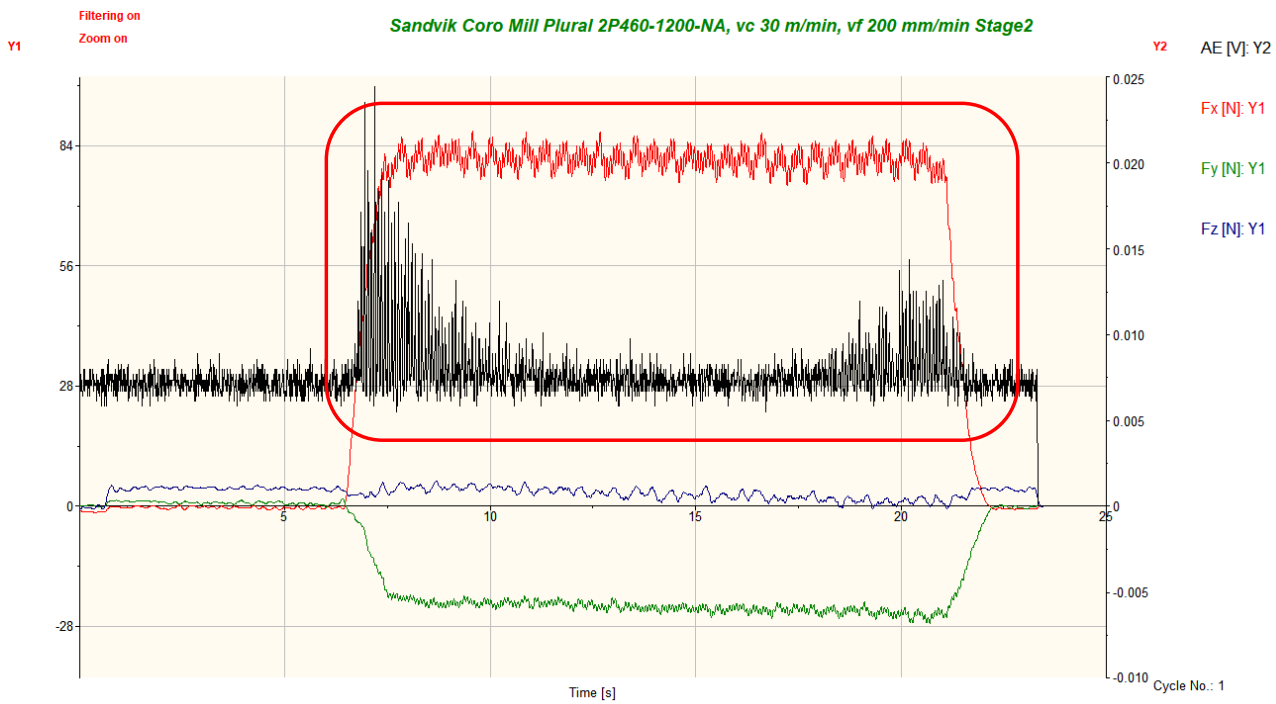

Fig. 10. $F_{x}, F_{y}, F_{z}$ and $A E$ values changes during milling GFRP with Coro Mill Plural 2P460-1200NA tool, Stage 2.

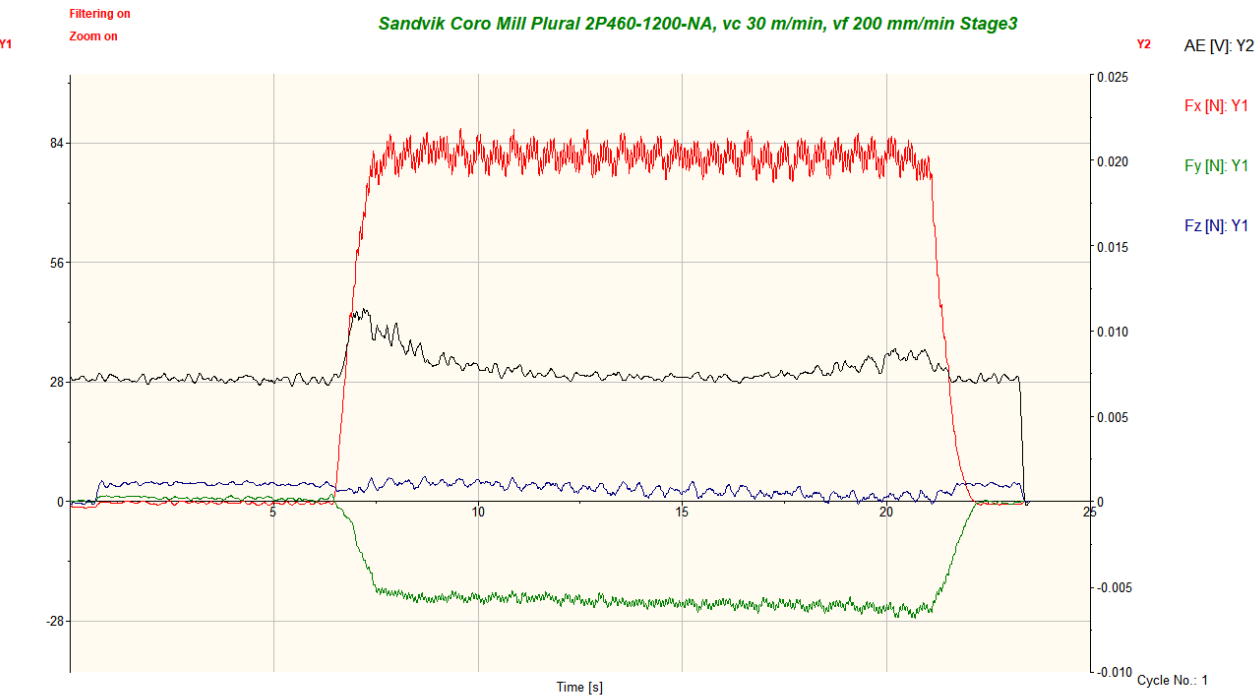

Fig. 11. $F_{x}, F_{y}, F_{z}$ and $A E$ values changes during milling GFRP with Coro Mill Plural 2P460-1200NA tool, Stage 3.

\section{Discussion and conclusions}

When analysing the turning of the RenShape ${ }^{\circledR}$ BM 5035 material, a relatively high sensitivity of the AE signal to the changes taking place in the process was found. RenShape ${ }^{\circledR}$ BM 5035 material is a polyurethane with a porous structure (it has the ability to damp vibrations), it is easily machinable and the obtained cutting forces were characterized by low values. Despite this, an increase in the value of the AE signal was observed at the moment of penetrating the workpiece, in a strong correlation with the courses of the cutting force components (Figs 13). In this case, the use of Stage 3 filtration (Fig. 3) is satisfactory for determining the state of the process. 
When analysing the turning of Hardox 400 material, a high sensitivity of the AE signal to changes occurring in the process was found, however, the nature of changes in the $\mathrm{AE}$ signal value is slightly different from the changes in the cutting force components. In the case of machining with a feed of $0.05 \mathrm{~mm} / \mathrm{rev}$, an increased and time-varying amplitude of changes in the AE value can be noticed than during machining with a feed of $0.9 \mathrm{~mm} / \mathrm{rev}$. While in the second case (Fig. 6 and 7), the use of digital filtering of the AE signal gives satisfactory results, in the case of processing with a feed rate of $0.05 \mathrm{~mm} / \mathrm{rev}$, a significant part of the information carried by the signal is lost as a symptom of an incorrect state of the process (amplitude "waving"). Changes in the amplitude value over time indicate an incorrect state of the process - feed rate (Fig. 4.5) was too small for machining this material and the tool performed friction work instead of cutting one. In the case of machining Hardox 400 with a feed rate of $0.19 \mathrm{~mm} / \mathrm{rev}$, the process conditions were more stable, despite the decreasing values of the $\mathrm{F}_{\mathrm{z}}$ component of the cutting force and the AE signal. This could be related to the heating of the material in the contact zone of the tool with the workpiece, which leads to a reduction in the specific cutting resistance and thus occurs as an improvement in the machining conditions.

Analyzing the milling of the GFRP composite with two different tools; general purpose Guhring 3715 cutter and Coro Mill Plural 2P460-1200-NA cutter with push-pull cutting edges - dedicated to processing fiber composites, AE signal was found to be useless in determining the process status. In the case of processing the GFRP composite, the AE signal remained unchanged, regardless of whether the processing was taking place or not - only a very slight change in the signal was observed when the tool entered the workpiece. In the case of GFRP machining with the Coro Mill Plural 2P460-1200-NA cutter, there was a significant increase in the amplitude and value of the AE signal at the time of penetration and exit of the tool from the workpiece, despite the quasi-invariable values of the cutting force components. Such a signal may lead to erroneous conclusions about the process state - in this case, it may be related to transient conditions due to the specific geometry of the tool and the reduction of cutting forces in the direction of the workpiece main axis.

Based on the literature review and the results of own work, the following conclusions were formulated:

- The acoustic emission signal can be a good signal for diagnosing the material removal machining process condition. Its great advantage is that there is no need to interfere with the tool-holder-workpiece system.

- The legitimacy of using AE signal measurements to monitor the state of the machining process should be considered each time, taking into account the mutual relations between the components of the machining process.

- The values of the machining force or force components generated in the process of machining workpieces are good as diagnostic signals. The biggest disadvantage of this solution is the necessity to interfere with the tool-holder-workpiece system and the very high price of measuring set-up.

- A better correlation between the AE signal and the cutting force components was observed during turning due to the AE sensor mounting close to the tool (rigid system, low damping).

- Worse correlation between the AE signal and the cutting force components was observed during milling due to mounting close to the workpiece (flexible system, greater damping)

\section{References}

1. T. Kałaczyński, M. Łukasiewicz, J. Musiał, R. Polasik, M. Szczutkowski, N. Dluhunovych, J. Wilczarska, T. Kasprowicz, Analysis of the diagnostic potential 
research thermovision in the technical state of combustion engine injectors assessment, 24th International Conference E ngineering M echanics, 357-360 (2018)

2. J. Bhaskaran, M. Murugan, N. Balashanmugam, Monitoring of hard turning using acoustic emission signal, J M ech Sci Technol, 26, pp. 609-615 (2012)

3. K. Dudzik, W. Labuda, The Possibility of Applying Acoustic Emission and Dynamometric M ethods for M onitoring the Turning Process, Materials, 13, pp. 2926 (2020)

4. A. Hamed, A.S. \& Rahimi, In-Process Monitoring of Nickel-Based Super Alloy Grinding Using the A coustic Emission M ethod, Russ J N ondestruct Test, 55, pp. 909917 (2019)

5. J. S. Kwak, J. B Song, Trouble diagnosis of the grinding process by using acoustic emission signals, International J ournal of M achine Tools and M anufacture, V olume 41, Issue 6, pp. 899-913 (2001)

6. S. Horiashchenko, K. Horiashchenko, J. Musiał, M ethodology of measuring spraying the droplet flow of polymers from nozzle, M echanika, 26, pp. 82-86 (2020)

7. S. Horiashchenko, J. Musiał, K. Horiashchenko, R. Polasik, T. Kałaczyński, M echanical Properties of Polymer Coatings A pplied to Fabric, Polymers, 12 (11), pp. 2684 (2020)

8. O. Synyuk, J. Musiał, B. Zlotenko, T. Kulik, Development of Equipment for Injection M olding of Polymer Products Filled with Recycled Polymer Waste, Polymers, 12, pp. 2725 (2020)

9. E. Dimla, D. Snr, M. Sortino, A N ew A pproach to the U se of V ibration Signals in ToolWear M onitoring in High Speed M etal Turning (2002)

10. H. Gao, M. X u, Intelligent Tool Condition Monitoring System for Turning Operations, In: W ang J., Liao X F., Y i Z, (eds) A dvances in N eural Networks - ISN N 2005, L ecture Notes in Computer Science, vol 3498, Springer, B erlin, Heidel berg (2005)

11. S. Kosaraju, V. G. Anne, B. B. Popuri, Online tool condition monitoring in turning titanium (grade 5) using acoustic emission: modelling, Int J A dv M anuf Technol, 67, pp. 1947-1954 (2013)

12. N. Li, Y. Chen, D. Kong, Force-based tool condition monitoring for turning process using v-support vector regression, Int J A dv M anuf Technol, 91, pp. 351-361 (2017)

13. V. Marinescu, I. Constantin, C. A postu, A daptive dimensional control based on in-cycle geometry monitoring and programming for CNC turning center, Int J Adv Manuf Technol, 55, pp. 1079-1097 (2011)

14. C. M. Nicolescu, M. Bejhem, On-Line Tool Condition Monitoring in Turning, Proceedings of the Thirty-First International Matador Conference, Palgrave, London (1995)

15. B. Sick, On-line tool wear monitoring in turning using neural networks, Neural Comput \& A pplic, 7, pp. 356-366 (1998)

16. S. Taibi, J. E. T. Penny, J. D. M aiden, M. B ennouna, M onitoring tool wear during the turning process, Condition Monitoring and Diagnostic Engineering Management, Springer, Dordrecht (1990)

17. E. Waschkies, C. Sklarczyk, E. Schneider, Tool Wear Monitoring at Turning and D rilling, Nondestructive Characterization of M aterials VI, Springer, B oston, M A (1994)

18. C. F. Bisu, M. Zapciu, O. Cahuc, Envelope dynamic analysis: a new approach for milling process monitoring, Int J Adv M anuf Technol, 62, pp. 471-486 (2012)

19. H. Fekrmandi, M. Unal, A. Baghalian, A non-contact method for part-based process performance monitoring in end milling operations, Int J Adv Manuf Technol, 83, pp. 13-20 (2016)

20. S. Garnier, M. Ritou, B. Furet, J. Y. Hascoet, Comparision and A nalisys of In-Process Tool Condition Monitoring Criterions in Milling, AMST'05 Advanced Manufacturing 
Systems and Technology, CISM International Centre for M echanical Sciences (Courses and L ectures), vol 486, Springer, V ienna (2005)

21. J. Lee, H. J. Choi, J. Nam, Development and analysis of an online tool condition monitoring and diagnosis system for a milling process and its real-time implementation, J Mech Sci Technol, 31, pp. 5695-5703 (2017)

22. J. Musiał, R. Polasik, T. Kałaczyński, M. Szczutkowski, M. Łukasiewicz, Milling efficiency aspects during machining of 7075 aluminium alloy with reference to the surface geometrical structure, In Proceedings of the 24th International Conference Engineering M echanics, Svratka, Czech Republic, 14-17 M ay, pp. 569-572 (2018)

23. M. K. Sinha, D. Setti, S. G hosh, P. V enkateswara Rao, A $n$ investigation on surface burn during grinding of Inconel 718, Journal of M anufacturing Processes, V olume 21, pp. 124-133 (2016)

24. R. Święcik, R. Polasik, Energetic aspects of the AEDG grinding process of Ti6Al4V titanium alloy, In AIP Conference Proceedings, AIP Publishing LLC.: M elville, NY, USA, V olume 2017, p. 020031 (2018)

25. R. Teti, T. Segreto, A. Caggiano, L. N ele, Smart M ulti-Sensor M onitoring in Drilling of CFRP/CFRP, Composite M aterial Stacks for A erospace A ssembly A pplications. A ppl. Sci., 10, pp. 758 (2020)

26. Y. Changfeng, W. Ting, X. W ei, H. X inchun, R. J unxue, Experimental study on grinding force and grinding temperature of A ermet 100 steel in surface grinding, Journal of M aterials Processing Technology, V olume 214, Issue 11, pp. 2191-2199 (2014)

27. T. Segreto, A. Caggiano, S. K aram, R. Teti, Vibration Sensor M onitoring of NickelTitanium A lloy Turning for M achinability Evaluation, Sensors, 17, pp. 2885 (2017)

28. Y. Qin, D. W ang, Y. Y ang, Integrated cutting force measurement system based on M EM S sensor for monitoring milling process, M icrosyst Technol, 26, pp. 2095-2104 (2020)

29. Y. Qin, Y. Zhao, Y. Li, A novel dynamometer for monitoring milling process, Int] Adv M anuf Technol, 92, pp. 2535-2543 (2017)

30. Y. Y ang, B. Hao, X. Hao, A Novel Tool (Single-Flute) Condition M onitoring M ethod for End Milling Process Based on Intelligent Processing of Milling Force Data by M achine L earning A Igorithms, Int. J. Precis. Eng. M anuf., 21, pp. 2159-2171 (2020)

31. S. M irifar, M . K adivar, B. A zarhoushang, First Steps through Intelligent Grinding U sing $M$ achine $L$ earning via Integrated $A$ coustic Emission Sensors, J. M anuf. M ater. Process, 4, pp. 35 (2020)

32. P. Sutowski, K. Nadolny, W. K aplonek, M onitoring of cylindrical grinding processes by use of a non-contact AE system, Int. J. Precis. Eng. M anuf., 13, pp. 1737-1743 (2012)

33. E. M. Rubio, R. Teti, Cutting parameters analysis for the development of a milling process monitoring system based on audible energy sound, J Intell M anuf., 20, pp. 43 (2009)

34. J. Musiał, S. Horiashchenko, R. Polasik, J. Musiał, T. Kałaczyński, M. M atuszewski, M. Śrutek, Abrasion Wear Resistance of Polymer Constructional Materials for Rapid Prototyping and Tool-M aking Industry, Polymers, 12, pp. 873 (2020) 